\title{
Electronic Commerce Research Profiles: Comparing E-Commerce and Information Systems Journals
}

\author{
Chien-Lung Hsu \\ Department of Marketing Management \\ Takming University of Science and Technology \\ alanhsu8399@gmail.com \\ Chun-Hao Chiang * \\ Department of Risk Control Management \\ Mega Financial Holding Company \\ hector@megaholdings.com.tw
}

\begin{abstract}
The rapid diffusion of information and mobile technologies has revolutionized the way we do business and how we conduct our daily lives. Electronic commerce (e-commerce or EC) has had an enormous impact on business practices and has become a new area of study for researchers in related fields. Thousands of papers on this subject have been published in the past two decades, most of which have been published in e-commerce (EC) journals. However, many such papers have been published in information systems (IS) journals. Information systems have become the core discipline that drives e-commerce research. The purpose of this research is to report on the profiles of e-commerce papers published in major EC and IS journals, and to determine whether papers that have appeared in EC journals differ from those published in IS journals. We surveyed EC papers published in ten major journals and conducted a bibliometric analysis. Our findings indicate that (1) more EC papers are published in EC journals, but papers published in IS journals are cited more often; (2) collectively, authors in the U.S. are the most prolific, followed by those in China and Taiwan; (3) more theories were used in recent papers than in earlier ones, and the TAM has been the most popular model; (4) B2C and consumer behavior have been the most popular subject areas for EC research; and (5) the core knowledge measured by the co-citation network was provided by the same group of authors in EC and IS journal publications.
\end{abstract}

Keywords: bibliometrics, electronic commerce, information systems, research profile, cocitation analysis, author ranking

Citation: Hsu, C. L. and Chiang, C. H. (2017). "Electronic Commerce Research Profiles: Comparing E-Commerce and Information Systems Journals," Pacific Asia Journal of the Association for Information Systems, 9(3), pp. 49-66. 


\section{Introduction}

The rapid diffusion of information and mobile technologies has revolutionized the way we do business and how we conduct our daily lives. The "smart" use of these technologies has changed the nature and business models of many industries such as retailing and wholesaling. Traditionally, electronic commerce models are divided into four major types: business-to-business (B2B), business-to-consumer (B2C), consumer-to-consumer (C2C), and consumer-to-business (C2B). Recently, hybrids such as the online to offline (O2O) and sharing economy models have gained more attention (Turban et al., 2015). According to a recent report from the U.S. Department of Commerce, "e-commerce sales remained strong in 2015 as web sales totaled $\$ 341.7$ billion for the year, a $14.6 \%$ increase over 2014's $\$ 298.3$ billion. This is the sixth year in a row that U.S. ecommerce sales have grown near or above 15\%" (Zaroban, 2016).

E-commerce has also generated huge impacts in China's markets. For instance, Taobao.com (the largest B2C platform) announced record-high sales of 120 billion $\mathrm{RMB}$ in a single day's transactions on November 11, 2016 (the Bachelor Shopping Day), which is an almost $32 \%$ increase from the 91 billion RMB record set in 2015. China has the potential to become the largest ecommerce market, if it has not done so already.

Given the significant impact of e-commerce on business, it is not surprising that research in e-commerce has grown significantly over the last decade. It would be interesting to examine the profiles of $e$ commerce studies. As a large portion of ecommerce researchers have their base in information systems, it is also interesting to see how papers published in e-commerce journals and IS journals might differ. Hence, the objectives of this research are as follows:

1. How has EC research grown and evolved in the past two decades?
2. Who are the major contributors of EC knowledge in EC and IS journals?

3. How have research topics changed in EC and IS journals?

\section{Background and Literature Review}

\section{E-Commerce Research}

The opening of the Internet for commercial use in 1991 created the e-commerce evolution. According to various estimates, more than 3 billion people have access to the Internet, and most of these users have made online purchases. The rapid growth of Internet users has also generated considerable research interest. A wide range of issues has been investigated and thousands of papers have been published over the past two decades. These papers have covered topics including conceptual framing, theoretical development, system design, website adoption, business model evaluation, and so on.

Given the vastness of the subject, any attempt to provide a comprehensive review of e-commerce literature is unrealistic. Below are a few sample studies which can provide a snapshot. Early on, lacovou et al. (1995) identified four factors that influence the EDI adoption practices of small firms: organizational readiness, external pressures to adopt, and perceived benefits. Bakos (1997) developed a model to show the role of buyer search costs in markets with differentiated product offerings. The impact of reducing these search costs was analyzed in the context of an electronic marketplace. Liang and Huang (1998) built and tested a transaction cost model to determine which products are more appropriate for marketing on the web and why they are more appropriate. A review of early papers was conducted by $\mathrm{Ngai}$ and Wat (2002).

In another research stream, Pavlou (2003) aimed to predict consumer acceptance of e- 
commerce by proposing a set of key drivers for engaging consumers in online transactions. Kim et al. (2008) develop a theoretical framework describing the trustbased decision-making process used by consumers for buying from websites. Lee and Turban (2001) developed a theoretical model for investigating the four main antecedent influences on consumer trust in Internet shopping: trustworthiness of the Internet merchant, trustworthiness of the Internet as a shopping medium, infrastructural (contextual) factors, and other factors (e.g., company size, demographic variables). Bhattacherjee (2001) examined the key drivers of consumers' intention to continue using business-to-consumer ecommerce services. Ba and Pavlou (2002) examined the extent to which trust can be induced by proper feedback mechanisms in electronic markets, and how some risk factors play a role in trust formation.

For e-commerce success, Palmer (2002) identified appropriate metrics for usability, design, and performance constructs to be used in studying consumer-focused websites. DeLone and McLean (2004) studied the measurements of e-commerce success, based on their information systems success model. In brief, there is a high volume of e-commerce research and it covers many different facets. For this reason, there a need to investigate the overall profile of this literature.

\section{Bibliometric Research in Electronic Commerce}

Bibliometrics is a quantitative tool for analyzing academic literature and showing the profile and trends of a particular research topic. Research outputs, countries, institutions, authors, major journals, cited articles, subject area and hot research topics can be analyzed using bibliometric methodologies. Bibliometrics has been widely applied to assess research performance (Noyons and Van Raan, 1994) and research impact (Gla"nzel and Moed, 2002), as well to analyze development trajectories, emerging trends and the knowledge structure of a given research field (Chen et al., 2012; Cruz and Teixeira, 2010). A few previous studies of ecommerce publications have been published. For example, Tsai (2015) classified e-commerce literature into eight categories. Other papers have reported on key research topics related to social commerce (Zhou et al., 2013), maps of the "core" of e-commerce research (Hsu et al., 2015).

Although these prior works have given insight into EC research, they did not show research profiles from different academic communities such as EC and IS. In particular, they did not explore whether different publication outlets prefer different research topics and attract different contributors. Hence, this paper intends to fill this gap by presenting a comprehensive survey of e-commerce papers that have appeared in EC and IS journals. More specifically, it aims to (1) identify significant publication patterns such as trends, and major subject categories between EC and IS journals; and (2) quantify research contributions from a variety of dimensions such as authors, theories, institutions, countries and journals.

\section{Research Methodology}

A bibliometric search was performed on the Web of Science database, selecting data from January 1, 1995, to December 31, 2015. In accordance with our goals, we used a systematic approach (Kitchenham, 2004) to collect this data, following these steps:

Step1: Raw data search. We started by
exploring the following digital
resource databases: Scopus,
Science Direct, ISI Web of Science,
Business Source Premier, Emerald,
Inspect, ACM Digital Library, IEEE
Xplore, and InderScience. We
searched the title, abstract, keywords,
and in some cases the full text,


depending on the search facilities of the databases. The following are the related search critera submitted to the databases: "Electronic Commerce*," "Internet Commerce*," "E-Commerce*," "eCommerce," or "eBusiness*."

Step2: Journal selection. We chose five representative journals each in the EC and IS fields to serve as paper sources. These journals often rank high in the number of published papers. The following IS Journals were selected: MIS Quarterly (MISQ), Management Science (MS), Journal of Management Information Systems (JMIS), Information \& Management (IM), and Information Systems Research (ISR). The following EC Journals were also selected: Electronic Commerce Research (ECR), International Journal of Electronic Commerce (IJEC), Decision Support Systems and Electronic Commerce (DSS), Journal of Electronic Commerce Research (JECR), and Electronic Commerce Research and Applications (ECRA). We obtained a total of 1,234 records as the initial dataset (including duplications); 600 from IS journals and 634 from EC journals.

Step3: Data cleansing. With the aid of Excel software, we removed duplicates, papers not published in English, and old papers published before 1990, resulting in 1,164 unique journal publications.

Step4: Title check. We reviewed the titles of all the publications to determine their relevance to our study, and excluded those whose titles were not highly related to electronic commerce.

Step5: Final relevance check. Finally, we scanned abstracts of these papers and removed any which were clearly irrelevant to this research topic. Table 1 shows the resulting data size from each step.

Table 2 shows the total number of papers retrieved and total citation number from each journal. IJEC was found to have published the highest number of EC papers (155), followed by DSS and ECRA. Among IS journals, IM ranked highest, having published 144 EC papers. This was followed by JMIS, ISR, and MS. With regard to total citations, however, MISQ claims the top slot at 4,226, followed by IJEC at 4,012, IM at 3,887, and ISR at 3,618.

\section{Table 1 - Number of papers included/excluded in each phase/stage}

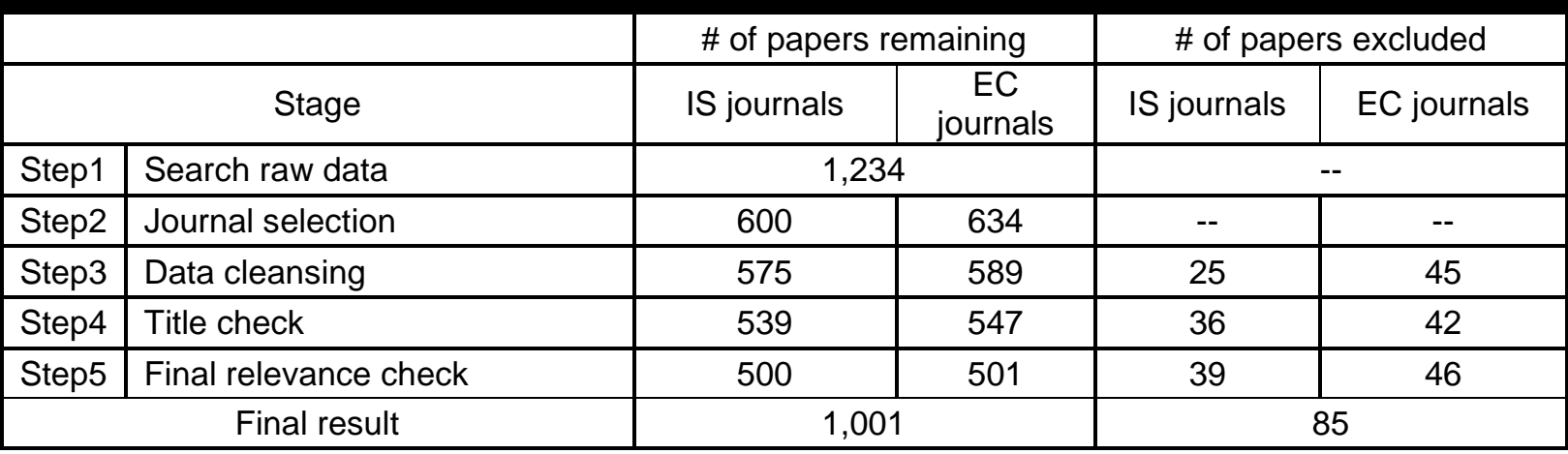




\begin{tabular}{|c|c|c|c|c|}
\hline $\begin{array}{c}\text { Journal } \\
\text { type }\end{array}$ & Journal & $\begin{array}{c}\text { No. of } \\
\text { publication }\end{array}$ & Citation no. & $\begin{array}{c}5 \text { Year } \\
\text { IF }\end{array}$ \\
\hline \multirow[t]{5}{*}{ EC } & International Journal of Electronic Commerce (IJEC) & 155 & 4,012 & 3.091 \\
\hline & Decision Support Systems (DSS) & 137 & 3,401 & 2.933 \\
\hline & Electronic Commerce Research and Applications (ECRA) & 115 & 1,108 & 2.34 \\
\hline & Journal of Electronic Commerce Research (JECR) & 48 & 329 & 1.306 \\
\hline & Electronic Commerce Research (ECR) & 46 & 248 & 2.02 \\
\hline \multirow[t]{5}{*}{ IS } & Information \& Management (IM) & 144 & 3,887 & 3.10 \\
\hline & Journal of Management Information Systems (JMIS) & 121 & 2,874 & 3.07 \\
\hline & Information Systems Research (ISR) & 95 & 3,618 & 3.75 \\
\hline & Management Science (MS) & 89 & 2,353 & 3.39 \\
\hline & MIS Quarterly (MISQ) & 51 & 4,226 & 8.49 \\
\hline
\end{tabular}

CiteSpace was used to produce and analyze co-citation networks among highly cited articles. CiteSpace is a Java-based freeware developed by $\mathrm{C}$. Chen from Drexel University, USA, which combines bibliometrics, information visualization, and data mining algorithms to provide interactive visualizations of citation patterns. CiteSpace supports author, article, journal, institution, and country nodes as well as phrases extracted from titles and abstracts of articles. Chen (2004) used CiteSpace I (the initial version of CiteSpace) to reveal turning points in superstring revolutions in physics. A new version called CiteSpace II appeared later and included three central concepts as new features: burst detection, betweenness centrality, and heterogeneous networks.
Recently, this software has become the world's most distinctive and influential visual software in the field of information analysis, and has been applied in different fields, including information retrieval (Rorissa and Yuan, 2012), knowledge visualization (Chen et al., 2012), agent-based computing (Niazi and Hussain, 2011), SSME in information systems (Hsu and Chiang, 2015) and Electronic Commerce Research in Information Systems and MIS Journals (Lin et al., 2016).

Figures 1 and 2 show the citation distribution of papers in EC and IS journals, respectively. IJEC and DSS are the top two cited journals, whereas MISQ, IM and ISR are three highly cited IS journals.

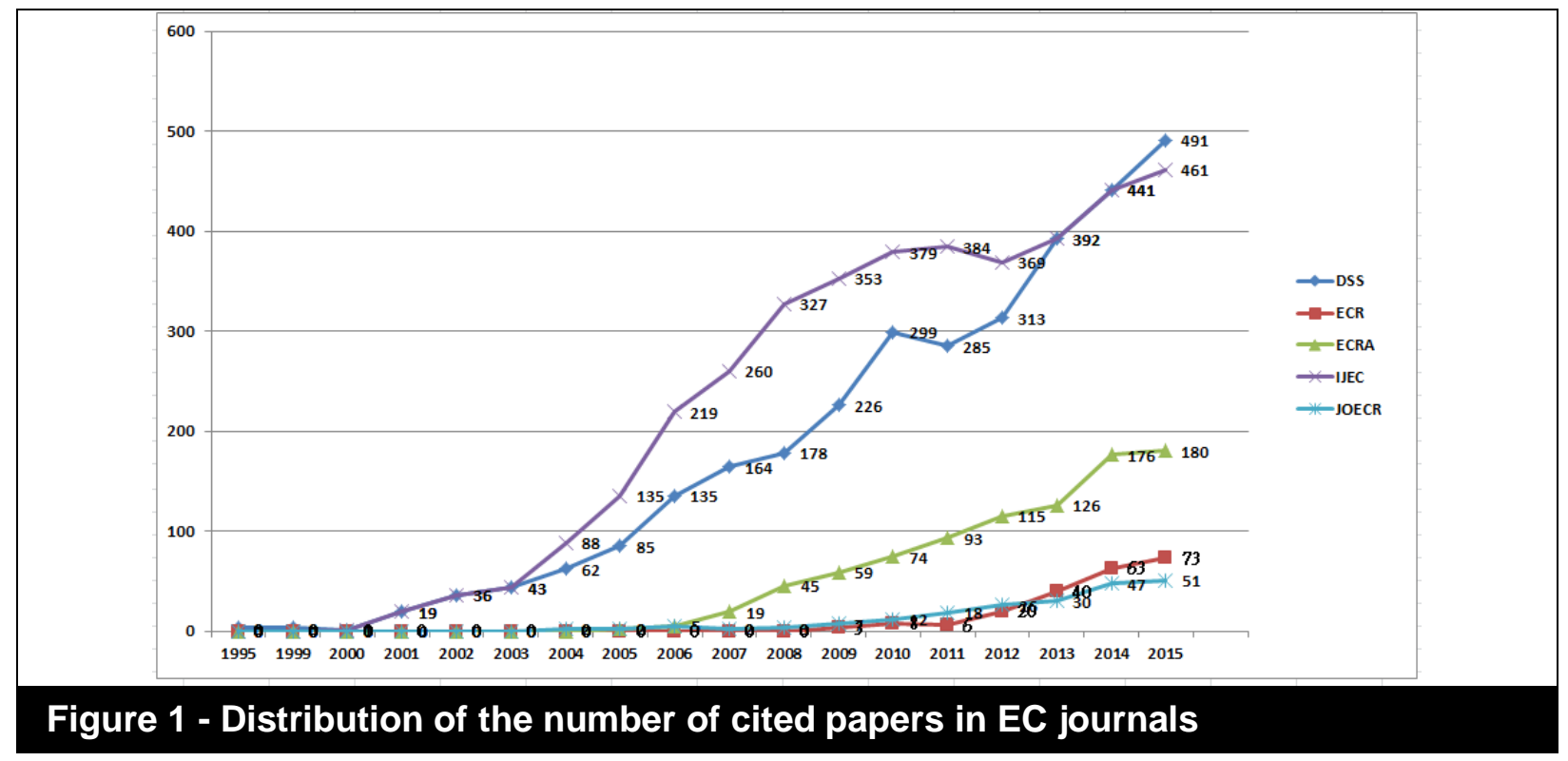




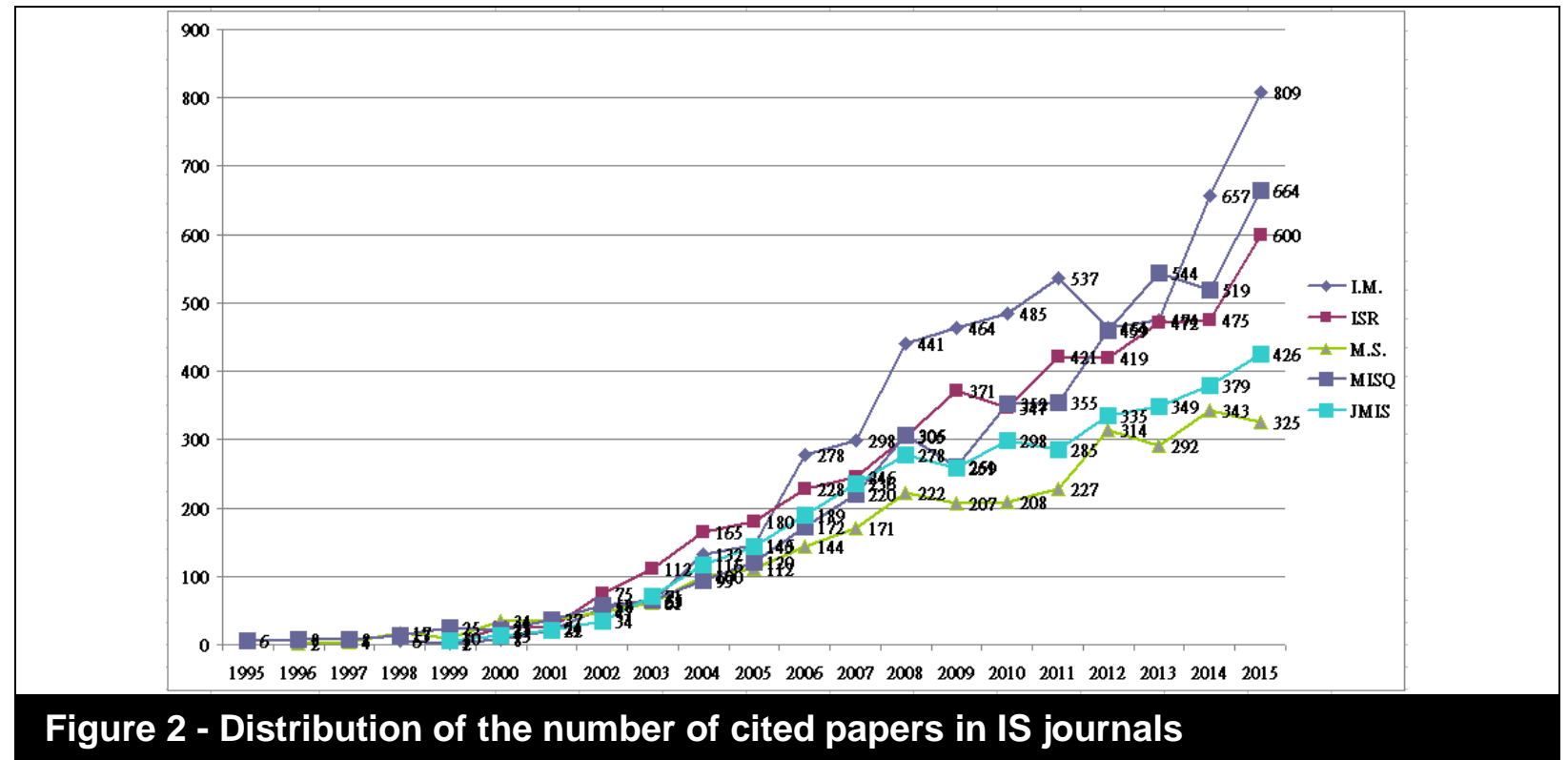

\section{Research Findings}

We analyzed the collected data to show the profiles of EC papers published in EC and IS journals. The findings are reported in this section.

\section{Growth Over the Years}

A total of 1,001 articles had records in this field. These papers were published between 1995 and 2015 (Fig 3.). The growth rate remained stagnant from 1997 to 2006, but gradually increased thereafter, reaching a peak in 2010. Although IS journals published more papers in the early years, EC journals started to publish more after 2007. This may be because IS journals were more established and had a better chance of capturing the trend. Citation numbers, however, show a different trend (Figure 4). This trend was hardly noticeable in the early years, but the number of papers published in IS journals surpasses that of the EC journals after 2001, even as both gained high momentum in growth. Around 2007, however, the number of articles published in EC journals eclipsed that of the IS journals.

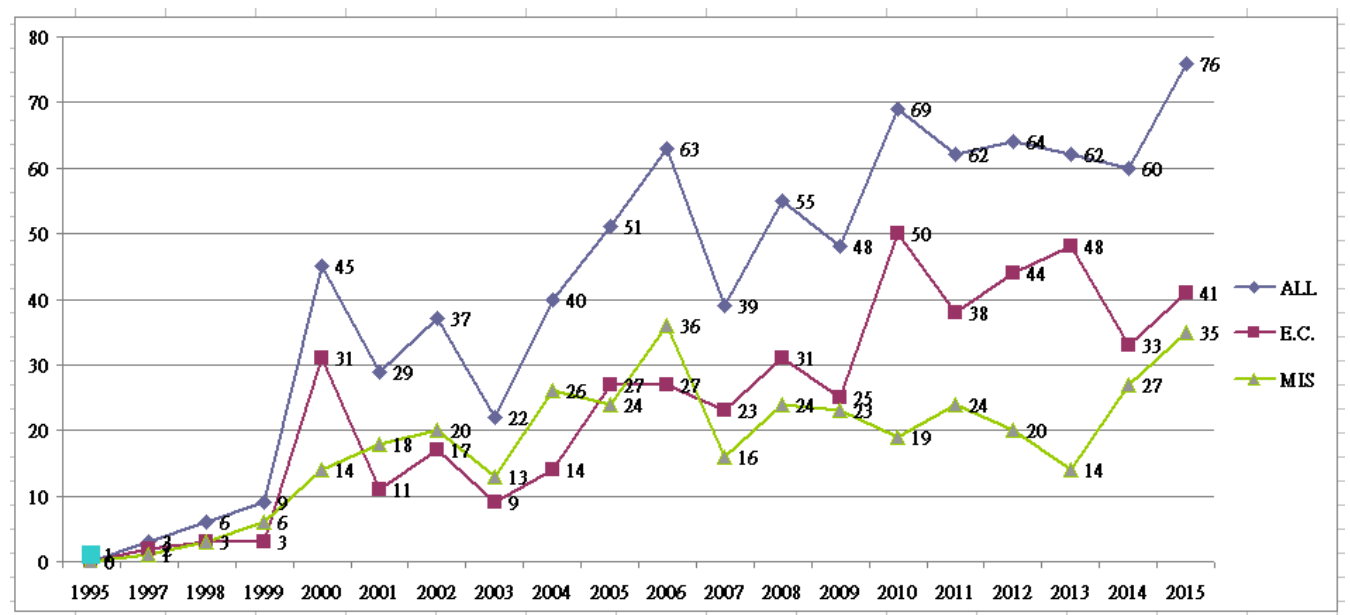

\section{Figure 3 - The growth trend of IS and EC Journal papers}




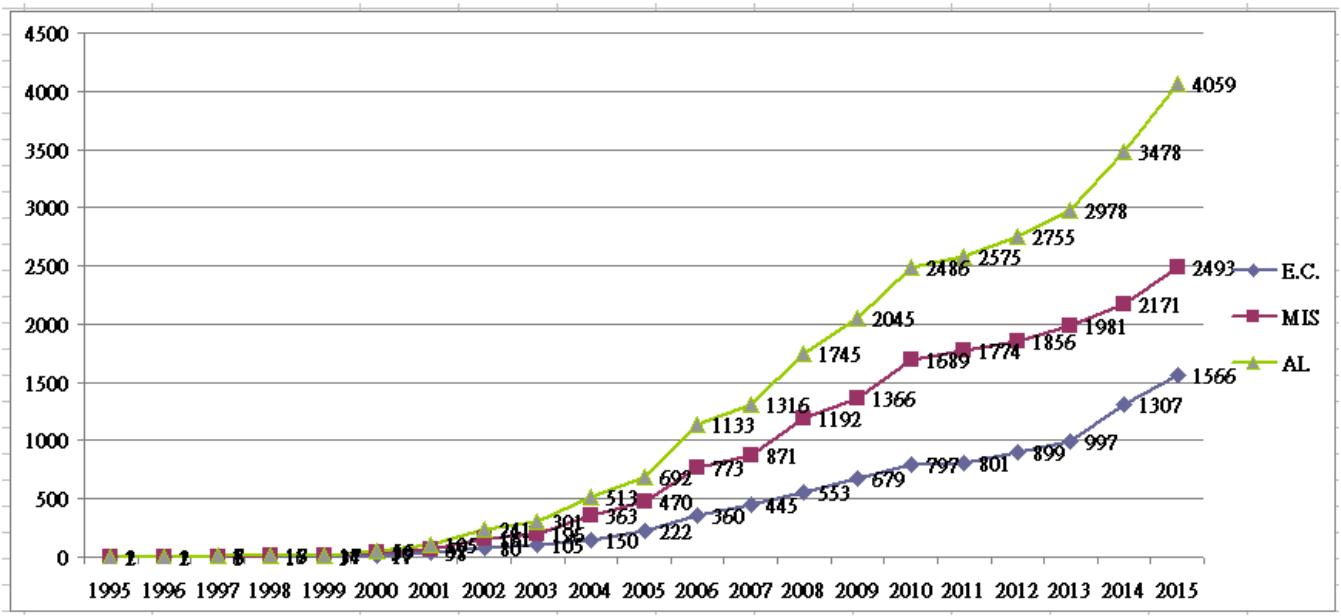

\section{Figure 4 - Citation numbers of IS and EC journal papers}

\section{Distribution by Country/Region}

The country distribution of paper publication is uneven. Table 3 shows the top 10 countries that have contributed to EC and IS journals, ranked by the total number of papers, indicating that a single country contributed a high percentage of the articles in this research field. The leading country was the United States (244 in IS, 219 in EC, for a total of 463), followed distantly by China (54 in IS, 93 in EC, for a total of 147) and Taiwan (23 in IS, 61 in EC, for a total of 61). The dominance of the U.S. is not surprising, since this pattern occurs in other scientific fields such as obstetrics and gynecology (Brandt et al., 2010) and orthopedic surgery (Kelly et al., 2010). The maturity of the U.S. academic community is the most likely reason for this pattern. Ecommerce has been the biggest arena for innovation and investment in recent years. This economic reality was clearly indicated by academic research interests. Thus, it comes as no surprise that, as a new economic power, China has contributed the second largest number of EC papers. Taiwanese scholars published more papers in EC journals (ranking third), but not as many in IS journals (where it ranked fourth). The pattern of Taiwan (also that of South Korea) is quite similar to that of China, but different from that of Canada. We suspect geographical closeness may play a role in scholars' choice of publication outlet.

\section{Table 3 - Top 10 countries/territories in EC publications}

\begin{tabular}{|c|c|c|c|c|c|c|}
\hline Ranking & Country & Total no. & IS & Ranking & EC & Ranking \\
\hline 1 & USA & 463 & 244 & 1 & 219 & 1 \\
\hline 2 & China / HK & 147 & 54 & 2 & 93 & 2 \\
\hline 3 & Taiwan & 84 & 23 & 4 & 61 & 3 \\
\hline 4 & Canada & 65 & 42 & 3 & 23 & 6 \\
\hline 5 & South Korea & 55 & 19 & 6 & 36 & 4 \\
\hline 6 & Singapore & 38 & 21 & 5 & 17 & 9 \\
\hline 7 & Germany & 34 & 8 & 5 & 26 & 5 \\
\hline 8 & Australia & 30 & 11 & 7 & 19 & 7 \\
\hline 9 & Netherlands & 26 & 8 & 8 & 18 & 8 \\
\hline 10 & Spain & 20 & 8 & 8 & 12 & 10 \\
\hline
\end{tabular}




\section{Popular Theories}

Despite the newness of this research area, extant theories have frequently been adopted in EC research. Table 4 shows the top 10 most used theories in EC research, ranked by the total number of articles. Not surprisingly, the TAM is ranked as the most popular theory in both EC and IS journals, followed by the information processing model and the consumer decision model. Pavlou (2003) was the most-cited published paper using the TAM. No significant difference was found between EC and IS journals. Figure 5 shows the frequency with which these theories were adopted by papers published in EC and IS journals. An interesting phenomenon is that the average number of theories mentioned in a paper increases over time. For example, we compared the data shown in Figures 3 and 5 , and found that the frequency of theory usage was 40 among 50 papers in EC journals in 2010, which increased to 69 among 41 papers in 2015.

\begin{tabular}{|c|c|c|c|c|c|c|}
\hline \multirow{2}{*}{ Rank } & \multirow{2}{*}{ Theory } & \multirow{2}{*}{$\begin{array}{c}\text { Total } \\
\text { no. }\end{array}$} & \multicolumn{2}{|c|}{ EC } & \multicolumn{2}{|c|}{ IS } \\
\hline & & & No & Ranking & No & Ranking \\
\hline 1 & Technology Acceptance Model (TAM) & 290 & 146 & 1 & 144 & 1 \\
\hline 2 & Information Processing Model (IPM) & 275 & 139 & 2 & 136 & 3 \\
\hline 3 & Consumer Decision Model (CDM) & 274 & 137 & 3 & 137 & 2 \\
\hline 4 & Decision-Making Process (DMP) & 259 & 133 & 4 & 126 & 4 \\
\hline 5 & IS Success Model (ISM) & 147 & 130 & 5 & 17 & 5 \\
\hline 6 & Diffusion of Innovation (Dol) & 30 & 19 & 7 & 11 & 7 \\
\hline 7 & Resource-Based Theory (RBT) ${ }^{*}$ & 29 & 16 & 6 & 13 & 6 \\
\hline 8 & Transaction Cost Economics(TCE) & 18 & 12 & 9 & 6 & 8 \\
\hline 9 & Theory of Production (ToP) & 17 & 14 & 8 & 3 & 9 \\
\hline 10 & Social Exchange Theory (SET) & 14 & 12 & 9 & 2 & 10 \\
\hline
\end{tabular}

Note: *resource based theory: including the Resource-Based View

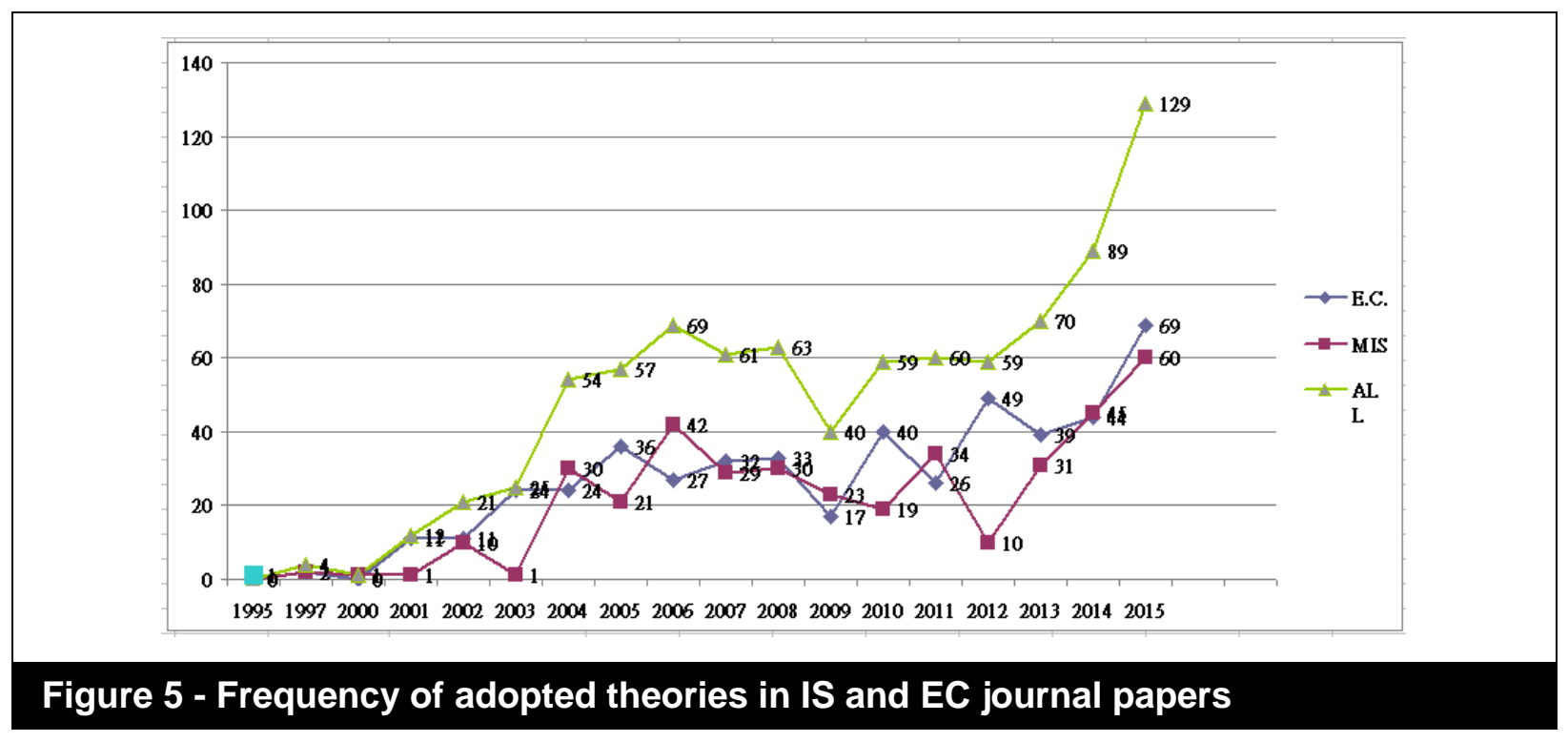




\section{Contributions by Institution}

It is also interesting to see the contribution of different institutions. Table 5 shows the contributions of the top ten universities. City University of Hong Kong ranks at the top
(42 papers in total), followed by Arizona State University and the National University of Singapore.

\section{Table 5 - Top 10 institutions ranked by number of papers published in EC and IS journals}

\begin{tabular}{|c|c|c|c|c|}
\hline Rank & Institution & Total No. & EC & IS \\
\hline 1 & CITY UNIVERSITY OF HONG KONG & 42 & 13 & 29 \\
\hline 2 & ARIZONA STATE UNIVERSITY & 29 & 21 & 8 \\
\hline 3 & NATIONAL UNIVERSITY OF SINGAPORE & 23 & 7 & 16 \\
\hline 4 & UNIVERSITY OF TEXAS AUSTIN & 21 & 8 & 13 \\
\hline 5 & UNIVERSITY OF HONG KONG & 13 & 8 & 5 \\
\hline 6 & UNIVERSITY OF ILLINOIS CHICAGO & 12 & 9 & 3 \\
\hline 7 & ERASMUS UNIVERSITY ROTTERDAM & 11 & 11 & 0 \\
\hline 8 & UNIVERSITY OF ILLINOIS URBANA CHAMPAIGN & 11 & 8 & 3 \\
\hline 9 & UNIVERSITY OF COLORADO BOULDER & 10 & 10 & 0 \\
\hline 10 & NATIONAL SUN YAT SEN UNIVERSITY & 9 & 9 & 0 \\
\hline
\end{tabular}

\section{Distribution of Research Topics}

E-commerce research covers a broad range of research topics. A classic categorization of e-commerce types includes business-tobusiness (B2B), business-to-consumer (B2C), consumer-to-business (C2B) and consumer-to-consumer (C2C). Figure 6 shows a relatively even paper distribution across these four types, with B2C having a slight advantage (28\%), and C2B appearing to be the weakest $(20.98 \%)$.

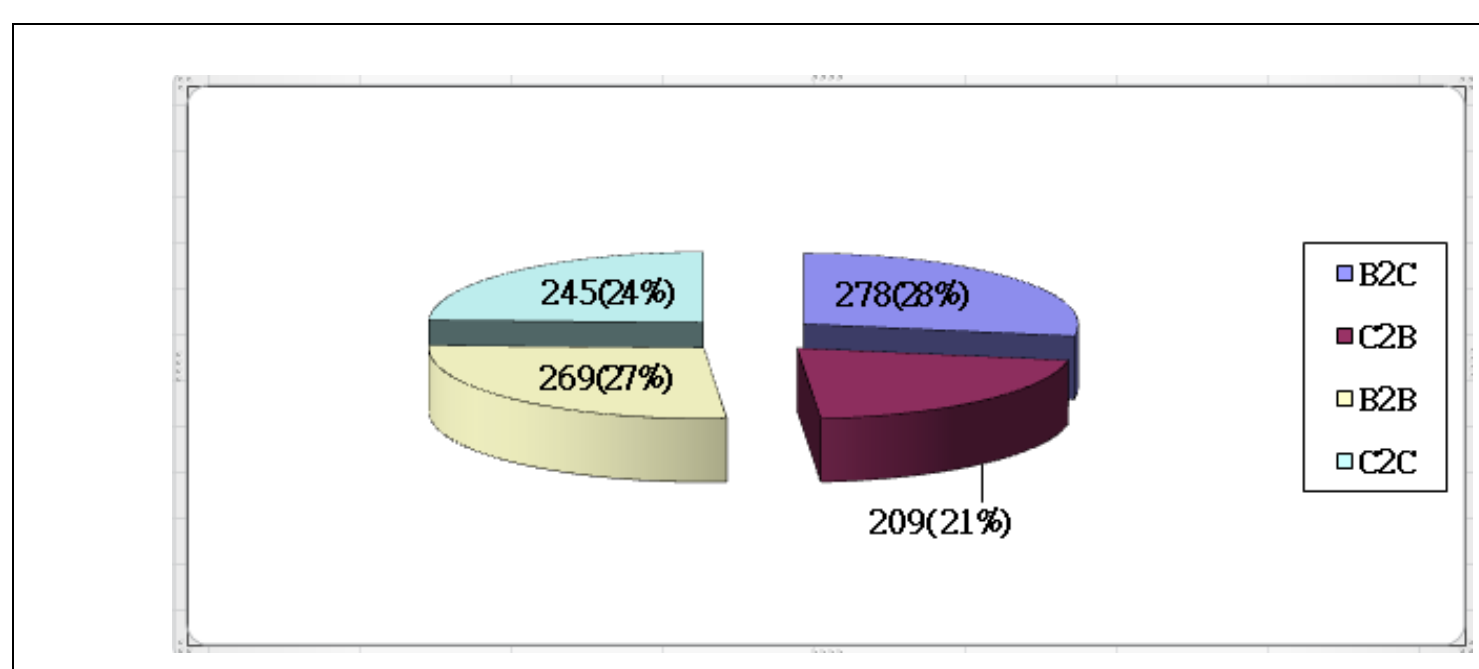

Figure 6 - Distribution by electronic commerce type 
We also used the classification scheme of Kalakota and Whinston (1997) to differentiate research topics. Figure 7 shows the result. The largest percentage of articles
$(32 \%)$ was related to consumer behavior (in both IS and EC journals), while the smallest was related to e-Consumer systems $(9.59 \%)$.

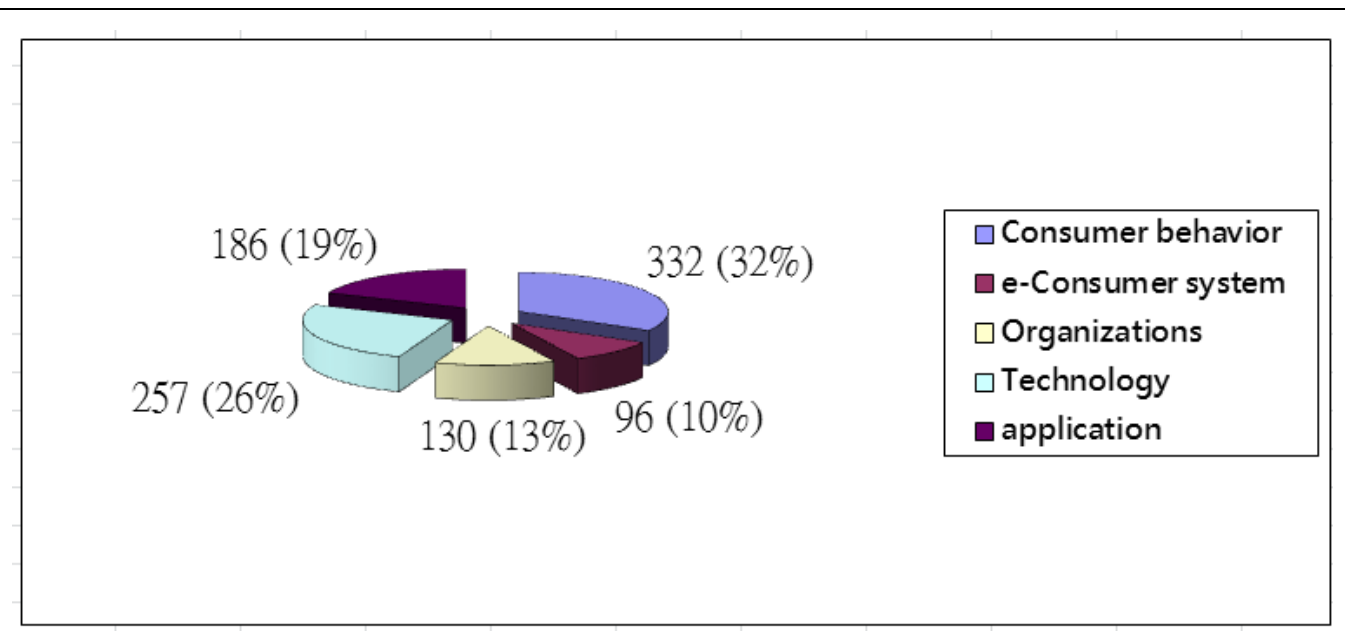

\section{Figure 7 - Topic distribution by main focus}

The details of the distribution across different topic categories are found in Table 6 . We can see that consumer behavior, as the largest group, can be divided into six subareas. Three areas make up a large proportion of this category: trust (60 articles: $11.47 \%$ in $\mathrm{EC}$ and $12.93 \%$ in IS), antecedents (74 articles: $11.13 \%$ in EC and $11.46 \%$ in IS), and influence (62 articles: $11.45 \%$ in EC and $10.36 \%$ in IS). Since a paper may have multiple categories, the numbers do not add up to $100 \%$. This reflects the fact that trust plays a major role in e-commerce because, unlike traditional transactions, trading parties do not see each other during the process. However, the large amount of related published articles may also indicate a certain herd behavior, which may inhibit the development of new knowledge.

The second largest number of articles is related to technology, "support system" (61 articles) is the major key term in this category. This is understandable since ecommerce relies on the support of technology. This area is followed by "commerce" (56) and electronic payment technology (46).
To illustrate the evolution of this research area via these identified key terms, Figure 8 shows the time map of research areas (the minimum number of keywords was 30 , and the number of terms selected was 59). Those in the green color are older publications; recent publications are shown in orange/red. The most commonly used keywords in the 2006-2008 time period were: marketing, price, online, channel, profit. From 2008-2010, the most common keywords were: trust, antecedent, survey, and belief (near the center, in yellow). The most common keywords used from 2010 to 2015 were: influence, determinant, intention, purchase, and reputation (near right, in red). This clearly shows that research interests evolve over time.

We also used the classification scheme of Kalakota and Whinston (1997) to differentiate research topics. Figure 7 shows the result. The largest percentage of articles $(32 \%)$ was related to consumer behavior (in both IS and EC journals), while the smallest was related to e-Consumer systems (9.59\%). 
Figure 9 shows the time mapping of topic citations (the minimum number of keywords: 15; threshold: 78 ), in which terms colored in blue are old, and those colored in red are current. For example, "information technology" and "electronic data interchange" in the bottom right are older terms, whereas "word of mouth" and "consumer reviews" in the upper left are more recent interests. The bottom right corner contains citation terms that were popular before 2007 (blue), and the upper left corner shows citation terms that were popular after 2010 (red).

\section{Table 6 - Distribution of articles by research topic}

\begin{tabular}{|c|c|c|c|}
\hline & \multirow{2}{*}{ Total } & EC & IS \\
\hline & & Percentage of subject & Percentage of subject \\
\hline \begin{tabular}{|l} 
Topic Classification \\
1. Consumer behavior
\end{tabular} & 332 & $53.73 \%$ & $51.17 \%$ \\
\hline 1.1 enjoyment & 28 & $4.61 \%$ & $3.82 \%$ \\
\hline 1.2 perception & 31 & $5.21 \%$ & $4.13 \%$ \\
\hline 1.3 royalty & 56 & $9.86 \%$ & $8.47 \%$ \\
\hline 1.4 influence & 62 & $11.45 \%$ & $10.36 \%$ \\
\hline 1.5 antecedent & 74 & $11.13 \%$ & $11.46 \%$ \\
\hline 1.6 trust & 81 & $11.47 \%$ & $12.93 \%$ \\
\hline 2. e-Consumer system & 96 & $57.87 \%$ & $49.27 \%$ \\
\hline 2.1 method & 8 & $5.91 \%$ & $4.76 \%$ \\
\hline 2.2 content & 13 & $7.80 \%$ & $6.87 \%$ \\
\hline 2.3 design & 18 & $9.76 \%$ & $8.57 \%$ \\
\hline 2.4 mechanism & 17 & $9.87 \%$ & $7.84 \%$ \\
\hline 2.5 collaboration & 14 & $9.91 \%$ & $8.76 \%$ \\
\hline 2.6 construction & 26 & $14.62 \%$ & $12.47 \%$ \\
\hline 3. Organizations & 130 & $60.65 \%$ & $51.64 \%$ \\
\hline 3.1 profit & 21 & $8.15 \%$ & $7.86 \%$ \\
\hline 3.2 partner & 15 & $6.04 \%$ & $5.14 \%$ \\
\hline 3.3 competitor & 16 & $6.94 \%$ & $5.34 \%$ \\
\hline 3.4 channel & 16 & $6.56 \%$ & $5.87 \%$ \\
\hline 3.5 cost & 14 & $7.54 \%$ & $5.33 \%$ \\
\hline 3.6 dimension & 15 & $8.73 \%$ & $6.12 \%$ \\
\hline 3.7 performance & 33 & $16.69 \%$ & $15.98 \%$ \\
\hline 4. Technology & 257 & $61.18 \%$ & $51.52 \%$ \\
\hline 4.1 social media & 13 & $4.51 \%$ & $2.73 \%$ \\
\hline 4.2 cloud & 14 & $2.59 \%$ & $1.93 \%$ \\
\hline 4.3 intelligent agent & 19 & $3.03 \%$ & $2.94 \%$ \\
\hline 4.4 methodology/algorithm & 14 & $3.92 \%$ & $3.12 \%$ \\
\hline 4.5 security & 34 & $6.46 \%$ & $5.19 \%$ \\
\hline 4.6 electronic payment & 46 & $9.36 \%$ & $8.26 \%$ \\
\hline 4.7 commerce & 56 & $14.60 \%$ & $13.54 \%$ \\
\hline 4.8 support system & 61 & $16.71 \%$ & $13.81 \%$ \\
\hline 5. Application & 186 & $58.60 \%$ & $47.21 \%$ \\
\hline 5.1 retailing & 2 & $1.14 \%$ & $0.45 \%$ \\
\hline 5.2 education & 9 & $4.02 \%$ & $3.12 \%$ \\
\hline 5.3 auction & 18 & $6.12 \%$ & $5.78 \%$ \\
\hline 5.4 advertising & 18 & $7.95 \%$ & $6.34 \%$ \\
\hline 5.5 risk & 22 & $7.31 \%$ & $6.98 \%$ \\
\hline 5.6 financing & 19 & $0.45 \%$ & $0.34 \%$ \\
\hline 5.7 agent & 19 & $8.32 \%$ & $6.76 \%$ \\
\hline 5.8 case & 37 & $11.31 \%$ & $8.46 \%$ \\
\hline 5.9 marketing & 42 & $13.12 \%$ & $9.43 \%$ \\
\hline Total & 1,001 & & \\
\hline
\end{tabular}




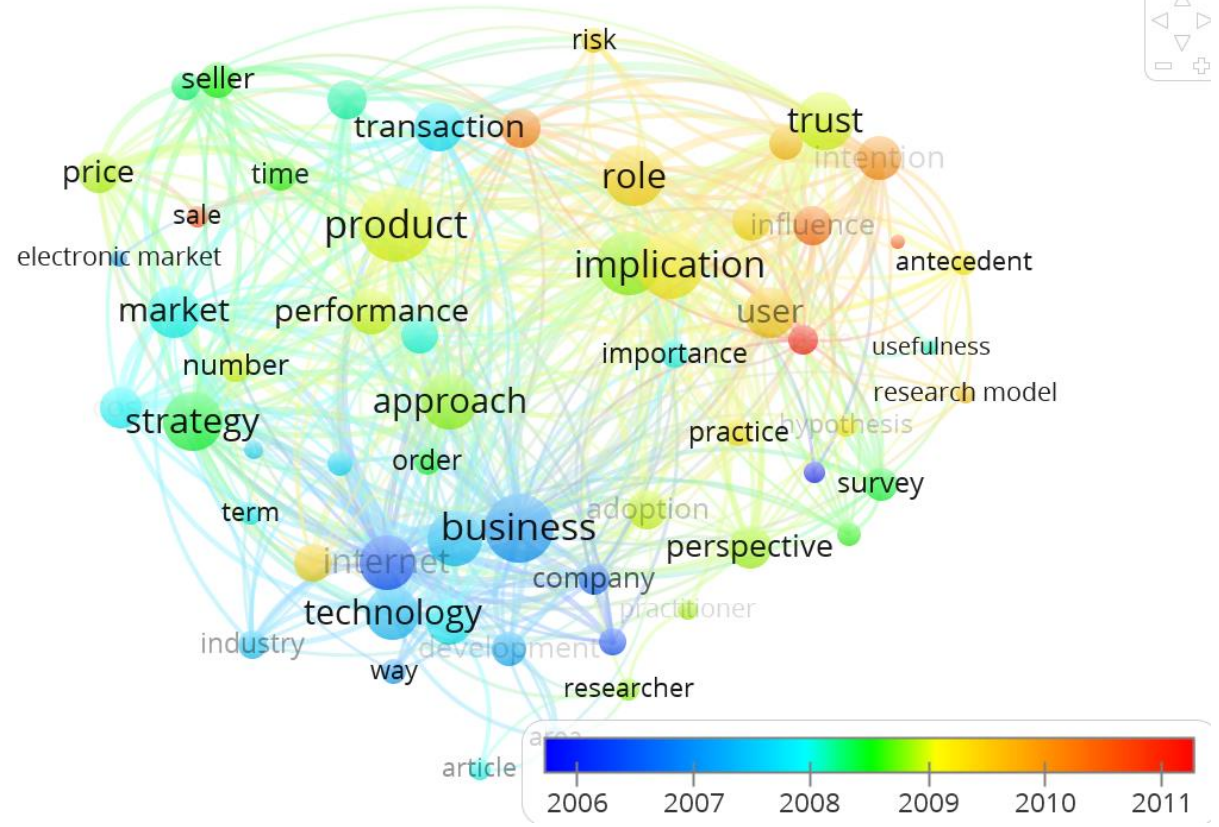

Figure 8 - Time Map of Topics

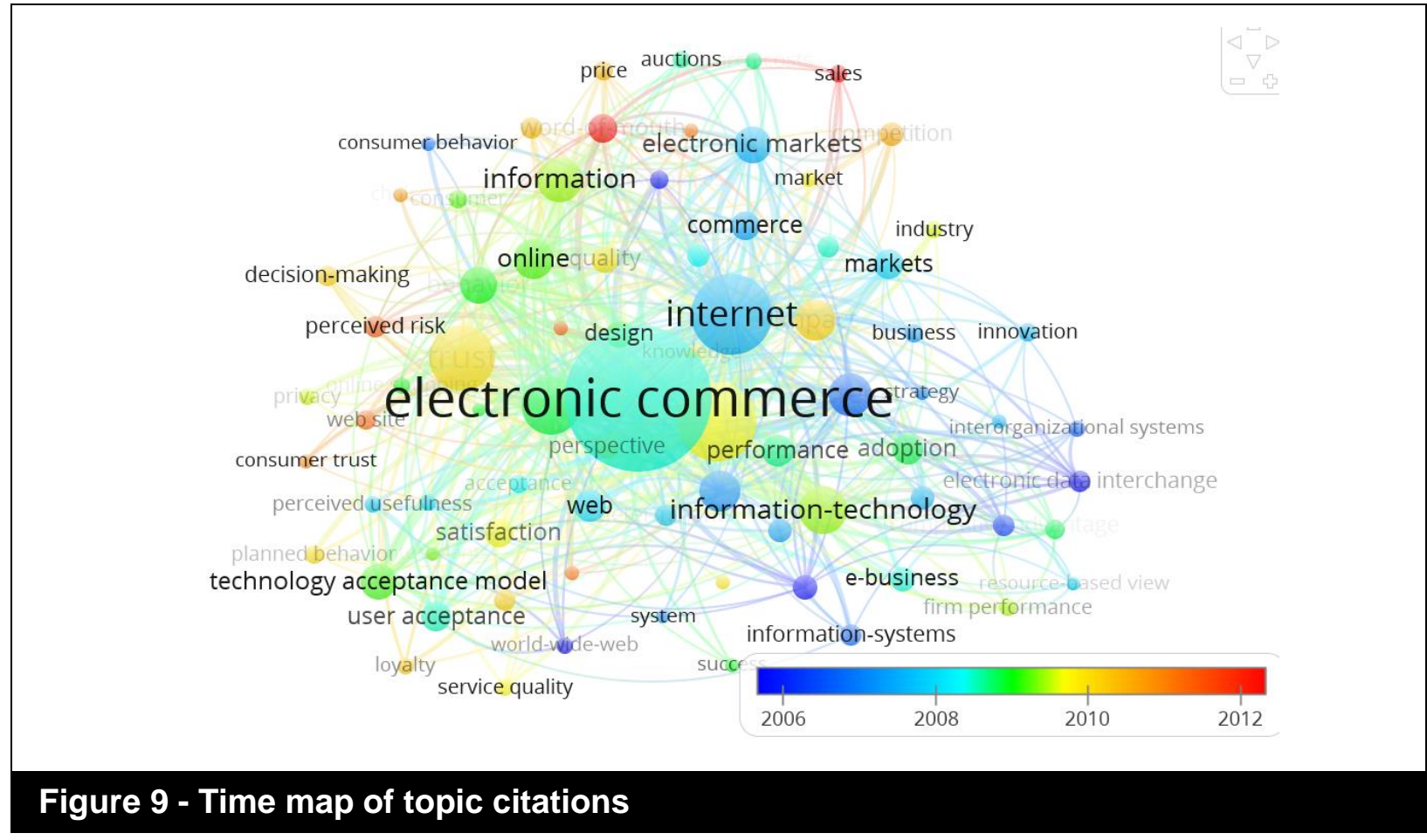




\begin{tabular}{|c|c|c|c|c|c|c|c|}
\hline \multirow{2}{*}{ Classification topics } & \multicolumn{4}{|c|}{ Num. of citations } & \multirow{2}{*}{ Num. of articles $(A)$} & \multirow{2}{*}{ Num. of citations (B) } & \multirow{2}{*}{ Average citations } \\
\hline & B2C & B2B & C2B & $\mathrm{C} 2 \mathrm{C}$ & & & \\
\hline 1. Consumer behavior & 946 & 683 & 1,253 & 587 & 332 & 3,498 & 10.54 \\
\hline 1.1 trust & 284 & 213 & 377 & 166 & 28 & 1,069 & 38.18 \\
\hline 1.2 royalty & 69 & 56 & 145 & 65 & 31 & 363 & 11.71 \\
\hline 1.3 influence & 321 & 193 & 350 & 174 & 56 & 1,069 & 19.09 \\
\hline 1.4 antecedent & 105 & 84 & 145 & 70 & 62 & 433 & 6.98 \\
\hline 1.5 enjoyment & 19 & 19 & 34 & 18 & 74 & 118 & 1.59 \\
\hline 1.6 perception & 148 & 118 & 202 & 94 & 81 & 593 & 7.32 \\
\hline 2. e-Commerce system & 543 & 659 & 532 & 633 & 96 & 2,398 & 24.98 \\
\hline 2.1 design & 200 & 355 & 177 & 356 & 8 & 342 & 42.75 \\
\hline 2.2 content & 63 & 91 & 59 & 96 & 13 & 337 & 25.92 \\
\hline 2.3 collaboration & 13 & 37 & 13 & 22 & 18 & 113 & 6.28 \\
\hline 2.4 mechanism & 127 & 81 & 125 & 73 & 17 & 437 & 25.71 \\
\hline 2.5 method & 135 & 86 & 153 & 78 & 14 & 482 & 34.43 \\
\hline 2.6 construction & 6 & 10 & 6 & 9 & 26 & 61 & 2.35 \\
\hline 3. Organizations & 819 & 706 & 785 & 582 & 130 & 2,923 & 22.48 \\
\hline 3.1 performance & 173 & 338 & 165 & 254 & 21 & 960 & 45.71 \\
\hline 3.2 cost & 235 & 132 & 214 & 123 & 732 & 696 & 48.8 \\
\hline 3.3 profit & 46 & 35 & 55 & 33 & 16 & 197 & 12.31 \\
\hline 3.4 competitor & 23 & 18 & 26 & 17 & 16 & 114 & 7.13 \\
\hline 3.5 partner & 88 & 34 & 54 & 18 & 14 & 225 & 16.07 \\
\hline 3.6 channel & 146 & 91 & 145 & 82 & 15 & 494 & 32.93 \\
\hline 3.7 dimension & 109 & 59 & 127 & 56 & 33 & 381 & 11.55 \\
\hline 4. Technology & 514 & 623 & 457 & 589 & 257 & 2,211 & 8.60 \\
\hline 4.1 security & 58 & 101 & 50 & 114 & 13 & 353 & 27.15 \\
\hline 4.2 commerce method & 87 & 136 & 79 & 154 & 14 & 487 & 34.79 \\
\hline 4.3 social media & 19 & 34 & 16 & 39 & 19 & 138 & 7.26 \\
\hline 4.4 cloud & 3 & 8 & 3 & 5 & 14 & 49 & 3.50 \\
\hline 4.5 Intelligent agent & 27 & 21 & 31 & 19 & 34 & 128 & 3.76 \\
\hline 4.6 electronic payment & 33 & 48 & 33 & 49 & 46 & 194 & 4.22 \\
\hline 4.7 support system & 93 & 196 & 89 & 146 & 56 & 554 & 9.89 \\
\hline 4.8 methodology / algorithm & 193 & 78 & 155 & 62 & 61 & 518 & 8.49 \\
\hline 5. Application & 947 & 993 & 862 & 876 & 186 & 3,708 & 19.94 \\
\hline 5.1 retailing & 73 & 103 & 64 & 125 & 2 & 395 & 91 \\
\hline 5.2 marketing & 301 & 528 & 269 & 489 & 9 & 1,617 & 18 \\
\hline 5.3 financing & 7 & 10 & 5 & 7 & 18 & 58 & 3.22 \\
\hline 5.4 advertising & 28 & 14 & 32 & 15 & 18 & 119 & 6.61 \\
\hline 5.5 auction & 94 & 63 & 86 & 3 & 22 & 276 & 12.55 \\
\hline 5.6 education & 9 & 21 & 8 & 15 & 19 & 83 & 4.37 \\
\hline 5.7 risk & 138 & 93 & 152 & 79 & 19 & 492 & 25.89 \\
\hline 5.8 case & 193 & 85 & 136 & 77 & 37 & 521 & 14.08 \\
\hline 5.9 agent & 100 & 72 & 106 & 62 & 42 & 368 & 8.76 \\
\hline
\end{tabular}

\section{Contributions by Author}

Authors are the main force behind the production of high-quality research. Tables 8 and 9 show the top 14 authors in IS and EC journals, ranked by the total number of authored articles. We also include the numbers of first author articles, second author articles, and single author articles. Among the top 14 authors in IS journals, 13 were affiliated with institutions in the USA, and one was from Canada: Benbasat, who is actually the most productive author of all. The most productive U.S. author is Pavlou, from Temple University.
Among the top researchers published in EC journals, Kauffman is the most productive, with 24 total papers, followed by Liang (10) and Westland (8). Among the top authors of EC journals, 6 were from the U.S. and two were from Taiwan. The Netherlands and England each had one author among the top published authors in EC journals. A comparison of these two tables reveals that only Robert Kauffman appears on both lists. This discrepancy indicates that $E C$ researchers have considerably different preferences when choosing journals for publication. Tables 8 and 9 in the above section show that co-authorship is very popular in both EC and IS research. 


\begin{tabular}{|c|c|c|c|c|c|c|}
\hline Author & Country & Institution & $\begin{array}{l}\text { Total } \\
\text { No. }\end{array}$ & $\begin{array}{c}\text { First } \\
\text { Author }\end{array}$ & $\begin{array}{l}\text { Second } \\
\text { Author }\end{array}$ & $\begin{array}{l}\text { Single } \\
\text { Author }\end{array}$ \\
\hline BENBASAT, I & Canada & University of British Columbia & 23 & 0 & 18 & 0 \\
\hline PAVLOU, PA & USA & Temple University & 11 & 5 & 3 & 1 \\
\hline WHINSTON, AB & USA & University of Texas, Austin & 8 & 0 & 1 & 0 \\
\hline $\mathrm{ZHU}, \mathrm{K}$ & USA & University of California, Irvine & 7 & 6 & 1 & 1 \\
\hline GUPTA, A & USA & University of Minnesota & 7 & 2 & 1 & 0 \\
\hline GHOSE, A & USA & NYU & 7 & 3 & 4 & 0 \\
\hline KAUFFMAN, RJ & USA & University of Minnesota & 6 & 1 & 3 & 0 \\
\hline GROVER, V & USA & Clemson University & 6 & 0 & 1 & 0 \\
\hline VISWANATHAN, S & USA & University of Maryland & 5 & 1 & 2 & 1 \\
\hline OVERBY, E & USA & Georgia Tech & 5 & 5 & 0 & 0 \\
\hline KRAEMER, KL & USA & University of California, Irvine & 5 & 0 & 5 & 0 \\
\hline $\mathrm{HU}, \mathrm{Y}$ & USA & Purdue University & 5 & 0 & 5 & 0 \\
\hline GEFEN, D & USA & Drexel University & 5 & 3 & 1 & 1 \\
\hline AGARWAL, R & USA & University of Maryland & 5 & 0 & 3 & 0 \\
\hline
\end{tabular}

\section{Table 9 - Top 10 authors published in EC journals}

\begin{tabular}{|l|l|l|c|c|c|c|}
\multicolumn{1}{|c|}{ Author } & \multicolumn{1}{|c|}{ Country } & \multicolumn{1}{|c|}{ Institution } & $\begin{array}{c}\text { Total } \\
\text { No. }\end{array}$ & $\begin{array}{c}\text { First } \\
\text { Author }\end{array}$ & $\begin{array}{c}\text { Second } \\
\text { Author }\end{array}$ & $\begin{array}{c}\text { Single } \\
\text { Author }\end{array}$ \\
\hline KAUFFMAN, RJ & USA & Arizona State University & 24 & 13 & 9 & 1 \\
\hline LIANG, TP & Taiwan & National Sun Yat-sen University & 10 & 7 & 1 & 1 \\
\hline WESTLAND, JC & USA & University of Illinois & 8 & 1 & 1 & 1 \\
\hline TAN, YH & Netherlands & Free University & 7 & 3 & 2 & 0 \\
\hline CHAU, PYK & $\begin{array}{c}\text { Peoples } \\
\text { Republic of } \\
\text { China }\end{array}$ & University of Hong Kong & 7 & 1 & 6 & 0 \\
\hline SHAW, MJ & USA & University of Illinois & 6 & 0 & 4 & 0 \\
\hline PAYNE, TR & England & University of Liverpool & 6 & 0 & 0 & 0 \\
\hline GUPTA, A & USA & University of Minnesota & 6 & 2 & 2 & 0 \\
\hline SU, BC & Taiwan & National Dong Hwa University & 5 & 2 & 2 & 2 \\
\hline RAO, HR & USA & SUNY, Buffalo & 5 & 0 & 0 & 0 \\
\hline KIM, DJ & USA & University of North Texas & 5 & 4 & 1 & 1 \\
\hline
\end{tabular}

\section{Co-Citation Relationships}

In this section, we analyze the co-citation map of 123 authors and 1,246 co-citation links (1996-2015, slice length=1 year for analysis). The result is shown in Figure 10. Co-citation indicates how different papers are related to each other. Papers $A$ and $B$ are co-cited if they are both cited by paper C. In our analysis, each node stands for one author; larger rings indicate papers that received more co-citations. Links between authors are co-citations. The most prominent node in our analysis is Fornell with 124 co-citations in EC and IS journals, collectively. The second most prominent node is Gefen, whose frequency is 116 in the network; McKnight ranks third with a frequency of 110.

Another concept in this analysis is centrality. There are different types of centrality. Our study investigated betweenness centrality, which is a measure of the structural importance of a node in a graph, as indicated by the number of shortest paths that pass through that particular node. A node with high betweenness centrality tends to connect disparate regions of a graph, linking clusters that might otherwise be disconnected (Brandes, 2001; Chen, 2006). In Table 10, the author with the highest centrality is Bakos (0.26), followed by 
McKnight (0.20) and $\mathrm{Ba}$ (0.20). This indicates that the paper authored by Bakos in 1997 provides a set of core knowledge that is useful to a variety of knowledge groups in the e-commerce field. This is supported by the fact that, at the time of this writing, Google Scholar gives the paper a citation number of 2,787. McKnight's contribution is different in that he has five papers in the co-citation arena. These papers are found to have focused on various topics including a trust building model, consumer trust, perceived information quality, B2B electronic commerce, and electronic data exchange. Table 10 lists the top 15 authors, based on co-citation analysis. In the table, we see similar co-cited authors in both EC and IS journals, albeit in different order.

\section{Figure 10 - A snapshot of the co-citation network}

\section{Table 10 - Top 15 authors by co-citation in EC and IS journals}

\begin{tabular}{|c|c|c|c|c|c|c|c|c|}
\hline \multirow{2}{*}{ Ranking } & \multirow{2}{*}{ Freq. } & \multirow{2}{*}{ Paper } & \multirow{2}{*}{ Centrality } & \multicolumn{2}{|c|}{ EC } & \multicolumn{2}{|c|}{ IS } \\
\cline { 5 - 9 } & & & Author & Freq. & Author & Freq. & Author \\
\hline 1 & 124 & 14 & 0.18 & Fornell C & 80 & Fornell C & 59 & Mcknight DH \\
\hline 2 & 116 & 6 & 0.05 & Gefen D & 59 & Gefen D & 57 & Gefen D \\
\hline 3 & 110 & 5 & 0.20 & Mcknight DH & 54 & Ba SL & 49 & Davis FD \\
\hline 4 & 98 & 2 & 0.10 & Mayer RC & 53 & Mayer RC & 45 & Mayer RC \\
\hline 5 & 95 & 6 & 0.20 & Ba SL & 51 & Mcknight DH & 44 & Fornell C \\
\hline 6 & 94 & 1 & 0.09 & Davis FD & 45 & Davis FD & 42 & Brynjolfsson E \\
\hline 7 & 79 & 3 & 0.12 & Brynjolfsson E & 37 & Brynjolfsson E & 41 & Ba SL \\
\hline 8 & 71 & 13 & 0.06 & Pavlou PA & 37 & Hoffman DL & 39 & Pavlou PA \\
\hline 9 & 69 & 3 & 0.15 & Jarvenpaa S L & 37 & Hair J & 37 & Bakos JY \\
\hline 10 & 66 & 1 & 0.26 & Bakos JY & 36 & Alba J & 33 & Jarvenpaa S L \\
\hline 11 & 64 & 2 & 0.03 & Podsakoff PM & 36 & Jarvenpaa S L & 30 & Malone TW \\
\hline 12 & 62 & 6 & 0.03 & Gefen D & 36 & Davis FD & 30 & Podsakoff PM \\
\hline 13 & 61 & 6 & 0.03 & Hoffman DL & 34 & Pavlou PA & 29 & Palmer JW \\
\hline 14 & 61 & 4 & 0.01 & Hair J & 34 & Podsakoff PM & 29 & Gefen D \\
\hline 15 & 55 & 2 & 0.04 & Palmer JW & 33 & Morgan RM & 26 & Pavlou PA \\
\hline
\end{tabular}




\section{Summary and Conclusion}

In this paper, we have drawn on bibliometric analysis to explore the profile of ecommerce research in EC and IS journals. We conducted analysis on EC related papers published in $5 \mathrm{EC}$ and 5 IS journals from 1996 to 2015. Our results indicate the following:

(1) The literature growth rate from 1996 to 2006 remained stagnant, but it gradually increased to reach a peak in 2006 for IS journals, and in 2010 for EC journals. The total number is the highest in 2015, collectively.

(2) More EC papers were published in EC journals after 2007, but more citations were generated from papers published in IS journals.

(3) Most papers in e-commerce were contributed by U.S. authors, followed by those in China and Taiwan. This may reflect the popularity of EC practice in the U.S. and China. EC and IS journals, however, have different groups of contributors with only one overlap among top ranked authors.

(4) Theories were popular in EC research. The most popular theory was the TAM, followed by IPM, CDM. There is an increasing trend of citing more theories in published papers, with more than one theory per paper.

(5) Publications covered a broad range of EC types. The most popular type of EC was B2C (28\%), while the least popular was C2B (20.87\%). The most popular research area was consumer behavior, while the least popular was applications. This indicates that these journals were more likely to publish theoretical papers, as opposed to application-oriented papers.

(6) Co-citation analysis indicates that the core knowledge underlying the citation of papers published in EC and IS journals was provided by the same group of authors.

Overall, this paper reports the profile of EC research from a bibliometric analysis of published papers. We found that different groups of main authors develop and publish new findings based on the work of a group of core authors, as measured by co-citation data.

This research has a few limitations. First, our analysis was based on publications retrieved from the Web of Science database using "electronic commerce" as the main key phrase. Thus, many papers that are related to e-commerce but did not include our keywords were not included in the analysis. This is a major restriction, in view of how a paper on Internet marketing using the e-business model would generally considered to be highly related to EC but may not have been retrieved using our search criteria. Another restriction is that we chose five EC journals and five IS journals as our target journals. The findings might be different if other EC or IS journals were included in our study. Nonetheless, the findings reported in this paper provide valuable information for those who are interested in the general profile of EC research over the past two decades.

\section{References}

Ba, S. L., and Pavlou, P. A. (2002). "Evidence of the Effect of Trust Building Technology in Electronic Markets: Price Premiums and Buyer Behaviour," MIS Quarterly, 26(3), pp.243-268.

Bakos, J. Y. (1997). "Reducing Buyer Search Costs: Implications for Electronic Marketplaces," Management Science, 43(12), pp.1676-1692.

Bhattacherjee, A. (2001). "An Empirical Analysis of the Antecedents of Electronic Commerce Service Continuance," Decision Support Systems, 32(2), pp. 201-214. 
Brandes, U. (2001). "A Faster Algorithm for Betweenness Centrality," Journal of Mathematical Sociology, 25(2), pp.163 -177 .

Brandt, J. S., Downing, A. C., Howard, D. L., Kofinas, J. D. and Chasen, S. T. (2010). "Citation Classics in Obstetrics And Gynecology: The 100 Most Frequently Cited Journal Articles in the Last 50 Years," American Journal of Obstetrics and Gynecology, 203(4), pp.355.e1-355.e7.

Chen, C. (2004). "Searching for Intellectual Turning Points: Progressive Knowledge Domain Visualization," Proceedings of the National Academy of Sciences of the United States of America, 101(1), pp. 5303-5310.

Chen, C. M. (2006). "CiteSpace II: Detecting and Visualizing Emerging Trends and Transient Patterns in Scientific Literature," Journal of the American Society for Information Science and Technology, 57(3), pp. 359-377.

Chen, H., Zhao, G. and Xu, N. (2012), "The Analysis of Research Hotspots And Fronts Of Knowledge Visualization Based on CiteSpace II," Lecture Notes in Computer Science, 7411, pp. 57-68.

Cruz, S. C., and Teixeira, A. A. (2010). "The Evolution of the Cluster Literature: Shedding Light on the Regional Studies-Regional Science Debate," Regional Studies, 44(9), pp.12631288.

DeLone, W. H. and McLean, E. R. (2004). "Measuring E-commerce Success: Applying The Delone \& Mclean Information Systems Success Model," International Journal of Electronic Commerce, 9(1), pp.31-47.

Gla"nzel, W., and Moed, H. F. (2002). "Journal Impact Measures in Bibliometric Research," Scientometrics, 53(2), pp.171-194
Hsu, C. L. and Chiang, C. H. (2015). "A Bibliometric Study of SSME in Information Systems Research," Scientometrics, 102(1), pp.1835-1865.

Hsu, C. L., Westland, J. C. and Chiang, C. H. (2015). "Electronic Commerce Research in Seven Maps," Electronic Commerce Research, 15(2), pp.147158.

lacovou, C. L., Benbasat, I. and Dexter, A. S.(1995). "Electronic Data Interchange and Small Organizations: Adoption and Impact of Technology," MIS Quarterly, 19(4), pp. 465-485.

Kalakota, R. and Whinston, A. (1997). Electronic Commerce: A Manager's Guide. Addison-Wesley. Reading.

Kelly, J. C., Glynn, R. W., O'Briain, D. E., Felle, P. and Mccabe, J. P. (2010). "The 100 Classic Papers of Orthopaedic Surgery: A Bibliometric Analysis," Bone \& Joint Journal, 92(10), pp.1338-1343.

Kim, D. J., Ferrin, D. L. and Rao, H. R. (2008). "A Trust-Based Consumer Decision-Making Model in Electronic Commerce: The Role of Trust, Perceived Risk, and Their Antecedents," Decision Support Systems, 44(2), pp. 544-564.

Kitchenham, B. A. (2004). "Procedures for Undertaking Systematic Reviews," Computer Science Department, Keele University (TR/SE-0401) and National ICT Australia Ltd (0400011T.1). Joint Technical Report.

Lee, M. K. O. and Turban, E. (2001). "A Trust Model for Consumer Internet Shopping," International Journal of Electronic Commerce, 6(1), pp.75-91.

Liang, T. P. and Huang, J. S. (1998). "An Empirical Study on Consumer Acceptance of Products in Electronic Markets: A Transaction Cost Model," Decision Support Systems, 24(1), pp. 29-43. 
Lin, A. J., Hsu, C. L. and Chiang, C. C. (2016). "Bibliometric study of Electronic Commerce Research in Information Systems \& MIS Journals," Scientometrics," 109(3), pp.1455-76.

Ngai, E. W. T. and Wat, E. K. T. (2002), "A Literature Review and Classification of Electronic Commerce Research," Information and Management, 39(5), pp. 415-429.

Niazi, M. and Hussain, A. (2011). "AgentBased Computing from Multi-Agent Systems to Agent-Based Models: A Visual Survey," Scientometrics, 89(2), pp. 479-499.

Noyons, E., and Van Raan, A. (1994). "Bibliometric cartography of scientific and technological developments of an $R$ \& D field: The case of optomechatronics." Scientometrics, 30 (1), pp. 157-173.

Palmer, J. W. (2002). "Web Site Usability, Design, and Performance Metrics," Information Systems Research,13(2), pp.151-167.

Pavlou, P. A. (2003). "Consumer Acceptance of Electronic Commerce: Integrating Trust and Risk With the Technology Acceptance Model," International Journal of Electronic Commerce,7(3), pp.101-134.

Rorissa, A. and Yuan, X. (2012). "Visualizing and Mapping the Intellectual Structure of Information Retrieval," Information Processing and Management, 48(1), pp.120-135.

Tsai, H. H. (2015). "The Research Trends Forecasted By Bibliometric Methodology: A Case Study In E-Commerce From 1996 To July 2015," Scientometrics,105(2), pp. 1079-1089.
Turban, E., King, D., Lee, J. K., Liang, T. P., and Turban, D. C. (2015). "Social Commerce: Foundations, Social Marketing, and Advertising," Electronic Commerce, pp. 309-364.

Zaroban, S. (2006). https://www.digital commerce360.com/2016/02/17/us-ecommerce-grows-146-2015/, access at 2017.10.18

Zhou, L., Zhang, P. and Zimmermann, H. D. (2013). "Social Commerce Research: An Integrated View," Electronic Commerce Research and Applications, 12(1), pp. 61-68.

\section{About the Authors}

Chien-Lung Hsu is an associate professor in the Department of Marketing Management at the Takming University of Science, Taiwan. He received his $\mathrm{PhD}$ degree in Department of Business Administration at National Taipei University (NTPU), Taiwan. His research interests are internet marketing, strategy marketing, ecommerce, service innovation and bibliometric study. He has published articles in Information and Management, Electronic Commerce Research, Scientometrics and Current Issues in Tourism.

Chun-Hao Chiang holds a Doctor of Information Management, National Chengchi University. He current works at the risk management department of Mega Financial Holding Co., Ltd., and mainly interested in financial risk management system, computer audit, e-commerce. He has published academic Papers in Taiwan Financial and Financial Quarterly, Scientometrics, Electronic Commerce Research, NTU Management Review, and Applied Economics. 